\title{
Evaluation of the convection moisture coefficient using various methods
}

\author{
Magda Vestfálová ${ }^{1, a}$ \\ ${ }^{1}$ KEZ, TU Liberec, Studentská 2, 461 17, Liberec 1, Czech Republic
}

\begin{abstract}
When we solute the issue of moisture transfer it is necessary to deal with two mechanisms: molecular mass transfer and the convective mass transfer. The driving force of transmission is the difference of the concentrations of moisture, respectively the difference of the partial vapor pressures. For the convective mass transfer is the key value the convective moister coefficient, which depends on many parameters, but for one particular experimental design will be influenced mainly by velocity. Experimentally detectable is the total moisture transfer caused by both mechanisms, it is the overall moisture transfer coefficient. In previous work we tried from a set of measured data during various modes and for different samples evaluate the dependence of the convection moister coefficient on the flow velocity for the concrete arrangement of the experiment. The aim of this study is to compare these values of the convection moister coefficient with the values calculated from criterial equations using the analogy of heat and mass transfer.
\end{abstract}

\section{Introduction}

The need to solute the issue of moisture transfer was established in the Department of Power Engineering Equipment in connection with the solution of the project TA01020313, which included just measuring the amount of moisture transferred due to various materials. Measurements carried out P. Dančová [1]. The result of measuring was the mass flow of steam through the different materials. In [2] we described the evaluation process of convection moisture coefficient from the measured amount of the transmitted moisture. The evaluation was performed using several assumptions. To verify their eligibility will be necessary to evaluate the convection moisture coefficient using another, independent method and compare obtained results.

\section{Description of the experiment}

In experimental measurements on Power Engineering Equipment TUL [1] the humid air flows along the both sides of a sample of rectangular shape. The inlet temperature and the inlet pressure of the airflow was the same on both sides of the sample. Inlet relative humidity of air was lower on one side of the sample (we mark it "dry" air). Inlet relative humidity of air on the other side of the sample was higher (we mark it "wet" air). Then the air flowed along the both sides of rectangular plate, there was a transfer of moisture from the "wet" air to "dry" air. Therefore, their relative humidity was changed. The changes in the relative humidity of the two streams between input and output were evaluated. The experiment was conducted in two different modes of moisture of the "wet" air and in ten different modes of volumetric flow of air.

\section{Determination of the convection moisture coefficient}

\subsection{Evaluation of the experiment}

From the measured values, we in [2] investigated the amount of steam $\dot{m}_{S}$, passing from one side of the sample to the other side, but assuming zero permeability of material, it means assuming, the dry air does not pass through the material (its mass flow on both sides of the sample is constant). For the known size of the area of the sample $A\left[\mathrm{~m}^{2}\right]$ we also in [2] determined areal density of the flow of moisture (steam) passing through the wall of the sample $j_{S}$. From that we calculated for each sample overall moisture transfer coefficient related to the difference of partial pressure of the steam in the "wet" and "dry" stream of air

$$
j_{S}=k_{S}\left(p_{S D A}-p_{S W A}\right),
$$

where

- $k_{S}\left[\frac{s}{m}\right]$ - overall moisture transfer coefficient through the planar wall,

\footnotetext{
${ }^{\mathrm{a}}$ Corresponding author: magda.vestfalova@tul.cz
} 


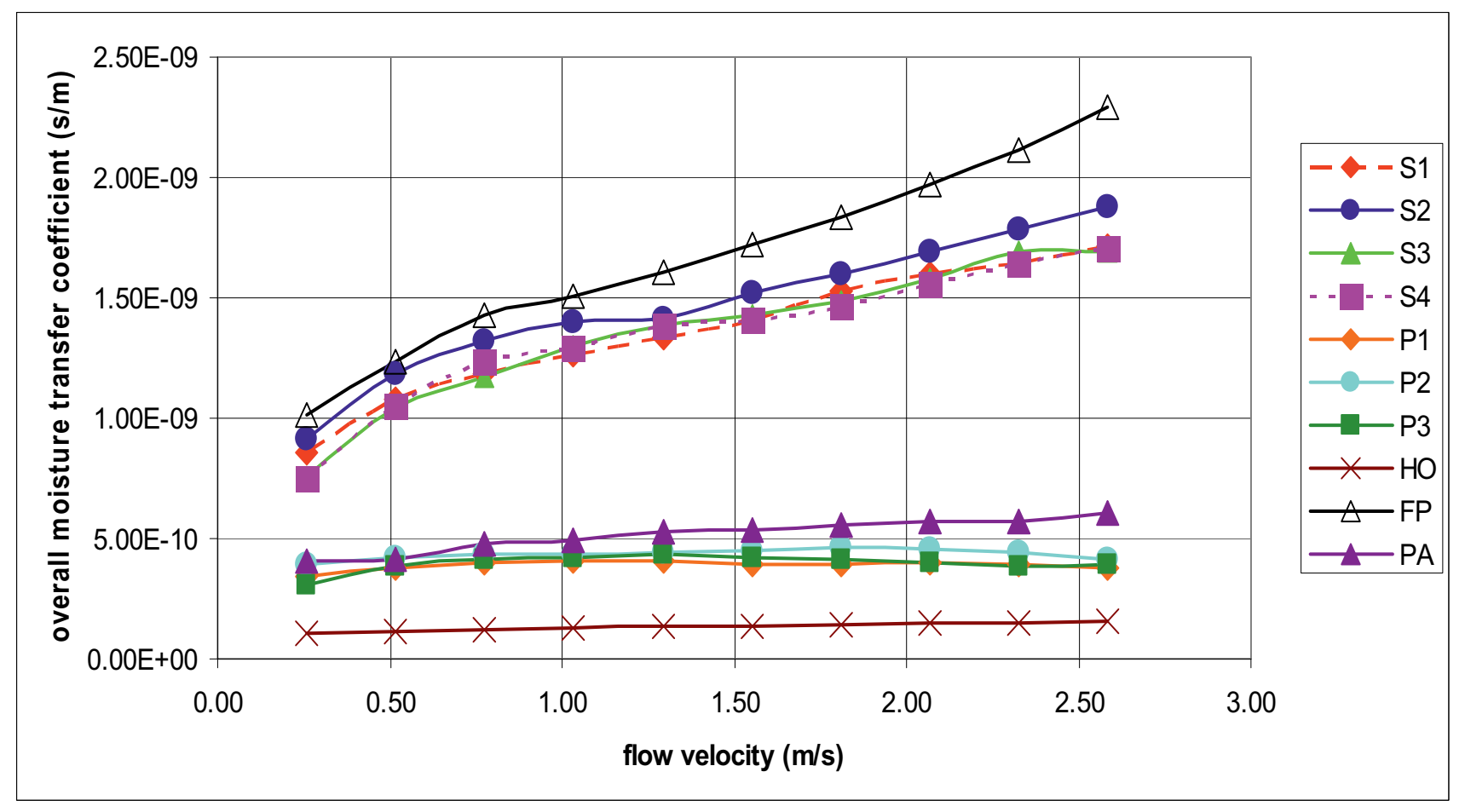

Figure 1. Overall moisture transfer coefficient [2].

$$
\frac{1}{k_{S}}=\frac{1}{\beta_{D A}}+\frac{t h}{D_{S}}+\frac{1}{\beta_{W A}}
$$

- $\quad p_{S D A}$, resp. $p_{S W A}[\mathrm{~Pa}]$ - partial pressure of the steam in the "dry", resp. "wet" air

- $t h[m]$ - wall thickness

- $\beta\left[\frac{s}{m}\right]$ - convection moisture coefficient between the flowing air and the planar wall

- $D_{s}[s]$ - coefficient of diffusivity of the moister regarding to the partial pressure of steam.

When comparing the results (figure 1), we found that the filter paper (FP) has the highest overall moisture transfer coefficient (even an order of magnitude higher than some of the other samples) and assuming that the convection moisture coefficient does not depend on the sample material (it means $\beta_{D A}$ is the same as $\beta_{W A}$ and additionally in all cases the same) it can be assumed that the filter paper has a higher diffusivity than all other samples. We use now next assumption: member of the diffusivity $\frac{t h}{D_{S}}$ is in relation for overall moisture transfer coefficient (2) for filter paper negligible against members with convection moisture coefficients $\frac{1}{\beta}$. Then, the overall moisture transfer coefficient is given to him (filter paper) only by the convection moisture coefficient
$k_{S}=\frac{\beta}{2}$. So, we obtained the values of the convection moisture coefficients for our arrangement of the experiment (figure 2).

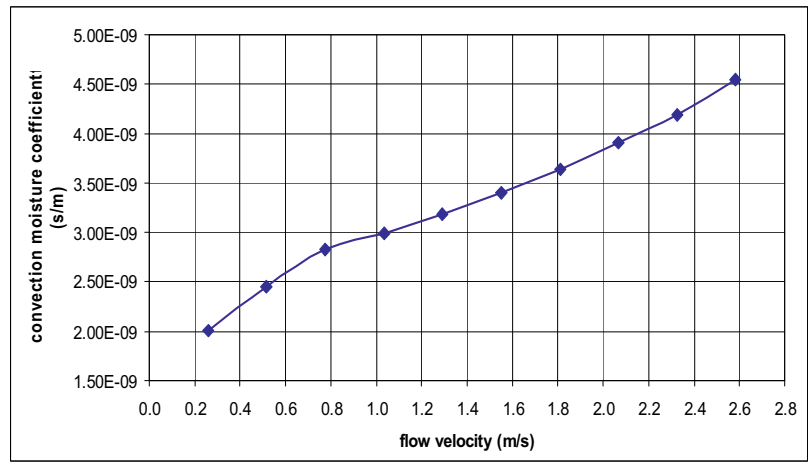

Figure 2. Convection moisture coefficient [2].

\subsection{Calculation of convection moisture coefficients from criteria equations}

Now we used to calculation of the convection moisture coefficient analogy between the mass transfer and the heat transfer: we assumed, that our case of "stationary mass transfer in the airflow along the planar plate" and the case "stationary heat transfer the planar plate" are analogy. So, if the coefficient of heat convection can be calculated from the equation for "stationary forced convection - wrap of the planar plate" in the form

$$
N u=N u(\operatorname{Re}, \operatorname{Pr})
$$


where

- $N u=\frac{\alpha d}{\lambda} \quad$ - Nusselt number

- $\alpha\left[\frac{W}{m^{2} K}\right]$ - coefficient of heat convection

- $d[m] \quad$ - characteristic dimension

- $\lambda\left[\frac{W}{m K}\right] \quad$ - coefficient of heat conduction

- $\operatorname{Re}=\frac{c d}{v} \quad$ - Reynolds number

- $c\left[\frac{m}{s}\right] \quad$ - velocity

- $v\left[\frac{m^{2}}{s}\right] \quad$ - kinematic viscosity

- $\operatorname{Pr}=\frac{v}{a} \quad$ - Prandtl number

- $a\left[\frac{m^{2}}{s}\right] \quad$ - thermal conductivity

we assumed, that the coefficient of mass transfer can be calculated from the analogy equation in the form

$$
S h=S h(\operatorname{Re}, S c),
$$

where

- $S h=\frac{\beta_{\rho} d}{D_{A B \rho}} \quad-$ Sherwood number

- $\beta_{\rho}\left[\frac{m}{s}\right]$ - convection moisture coefficient related to the difference of partial density of the $\operatorname{steam}\left(j_{S}=\beta_{\rho} \Delta \rho_{S}\right)$

- $d[m] \quad$ - characteristic dimension

- $D_{A B \rho}\left[\frac{m^{2}}{s}\right]$ - coefficient of diffusivity of the moister regarding to the partial density of the steam $\left(j_{S}=D_{A B \rho} \frac{d \rho_{S}}{d x}\right)$

- $S c=\frac{v}{D_{A B \rho}} \quad$ - Schmidt number

In our case, all measurements fall to the range of the laminar flow. As the first assumption we used the simplest criterial equation for laminar flow around plates (wrap of the planar plate) [4]

$$
S h=0.057\left(S_{c} \cdot \operatorname{Re}\right)^{0.78} \text {. }
$$

(In future it would be possible to test other published criterial equations for more accurate results.) To determine the coefficient of diffusivity of the vapor in air, we used the relationship [3]

$$
D_{A B \rho}=2.193 \cdot 10^{-6} \frac{1}{p}\left(\frac{T}{273}\right)^{1.8} \text {. }
$$

From the obtained values of Sherwood numbers we calculated the convection moisture coefficient for each measurement (it is for different speeds wrap). To compare the results of [2] was to be necessary to recalculate the convection moisture coefficient related to the difference of partial density of steam $\beta_{\rho}$ $\left(j_{S}=\beta_{\rho} \Delta \rho_{S}\right)$ to the convection moisture coefficient related to the difference of partial pressure of steam $\left(j_{S}=\beta_{p} \Delta p_{S}\right)$. The obtained results of the convection moisture coefficients we can see in figure 3 . Now, we can compare results (the convection moisture

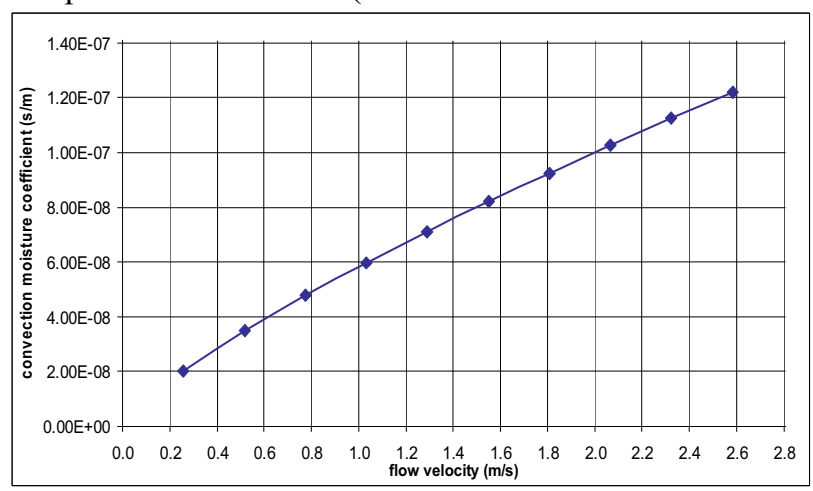

Figure 3. Convection moisture coefficient from criterial equation.

coefficients) obtained through the criterial equation (figure 3) with which in our preceding work in [2] (figure 2).

In [2] we calculated the coefficient of diffusivity $D_{S}$ for each material from the known dependence convection moisture (vapour) coefficient $\beta$ on the speed of the flow (figure 4) from

$$
D_{s}=\frac{t h}{\frac{1}{k_{S}}+\frac{2}{\beta}} \text {. }
$$

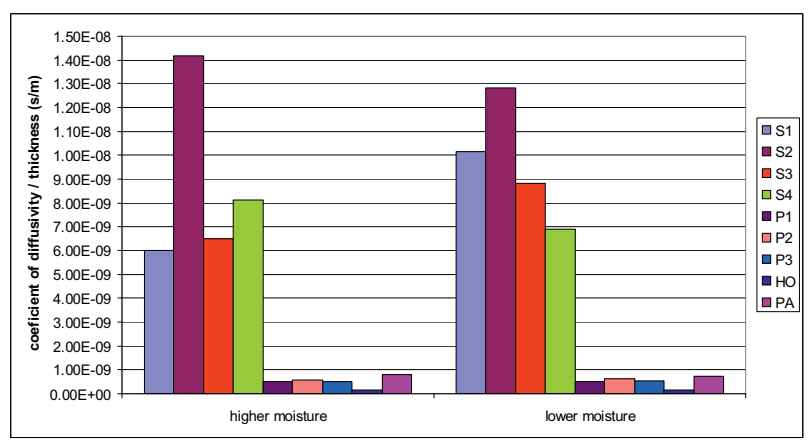

Figure 4. The coefficient of diffusivity on different samples of materials for two modes of experiments [2]. 
Now, it is necessary recalculated the coefficient of diffusivity $D_{S}$ from new values of convection moisture (vapor) coefficient $\beta$ (from criteral equations). The coefficient of diffusivity $D$ s obtaining from criterial equations relative to their thickness th we can see in figure 5 .

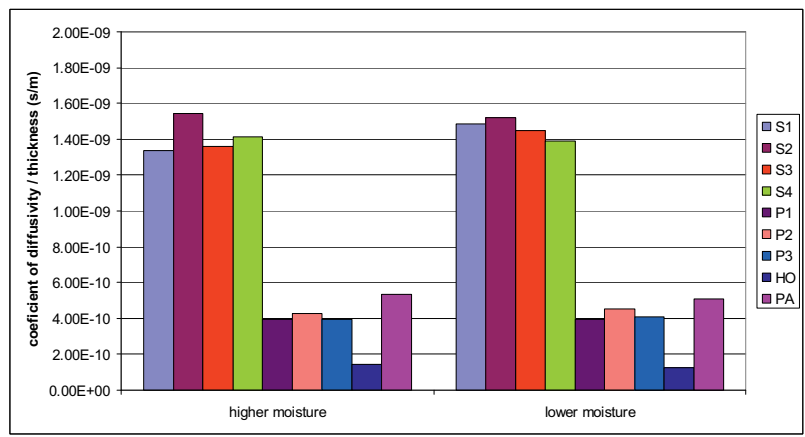

Figure 5. The coefficient of diffusivity on different samples of materials for two modes of experiments (from criterial equations).

\section{Conclusions}

- Results obtained from criterial equations are more than one order of magnitude higher than the results obtained in [2].

Assumptions used in [2] thus apparently not sufficiently justified!

- The assumption of neglecting the influence of high coefficient of diffusivity of the filtration material may be not correct.

- The assumption of the zero permeability of material (it means assuming, the dry air does not pass through the material) may be not correct.

- If we now calculated the coefficient of diffusivity $D_{s}$ of the samples [2] (figure 4) from newly discovered convection moisture coefficient $\beta\left[\frac{s}{m}\right]$ (still assuming that the means of $\beta$ on the side of "dry" air and on the side of "wet" air ate the same) we find that the differences occur only in samples, which value of overall moisture transfer coefficient $k_{S}\left[\frac{s}{m}\right]$ is comparable with overall moisture transfer coefficient of filtration paper (FP) - it means material S1, S2, S3 and S4. For the vast majority of samples (it is those which have a lower coefficient of diffusivity) do not appear significant differences.

- On the basis of other measurements it shows, that the assumption of the zero permeability of the filter paper was wrong! To use the method described in [2] it will be necessary to find some material with the high value of diffusivity and concurrently the zero permeability.
- If the results form method [2] and from criterial equations do not match even more for the suitable choice of materials, it will be necessary to develop another preferable method to their comparison.

\section{Acknowledgment}

Author gratefully acknowledges financial support by Czech Technological Agency under the project TACR TA01020313.

\section{References}

1. V. Dvořák, T. Vít, M. Vestfálová, P. Dančová, Entalpex, Zpráva KEZ pro TACR (2012)

2. M. Vestfálová, International Conference Experimental Fluid Mechanics 2012, $762-765$ (2012)

3. V. Vacek, V. Hlavačka, Přenos tepla a hmoty (1990)

4. M. Sazima, V. Kmoníček, J. Schneller, Teplo (1989)

5. M.S. Nasif, G.L. Morrison, M. Behnia, J. Applied Membrane Science \& Technology, 2, 31-46 (2005)

6. L.Z. Zhang, J.L. Niu, Journal of Heat Transfer, 124, 922-929 (2002) 